\title{
Síndrome del ganglio mesentérico cavitado
}

\section{Cavitating Mesenteric Lymph Node Syndrome}

\author{
A. Domínguez ${ }^{1}$ M. Noceti ${ }^{1}$ \\ 1 Área RM de cuerpo, Fundación Escuela de Medicina Nuclear \\ (FUESMEN), Mendoza, Argentina
}

Rev Argent Radiol 2018;82:48-49.

Estimados editores,

La enfermedad celíaca es una enteropatía crónica autoinmune que se caracteriza por la intolerancia al gluten, que afecta alrededor de 1:100 a 1:300 personas. ${ }^{1-3}$ El sindrome del ganglio mesentérico cavitado es una complicación rara y de mal pronóstico de la enfermedad celíaca, que consiste en la aparición de cambios quísticos en los ganglios mesentéricos. ${ }^{2-5}$
Address for correspondence Dr. Andrés Domínguez, MD, Fundación Escuela de Medicina Nuclear (FUESMEN), Garibaldi 405, CP: 5500 , Mendoza, Argentina (e-mail: andresdominguez82@gmail.com).

Se presenta un caso de un varón de 63 años de edad, que realizó una consulta por decaimiento y una pérdida de peso de $10 \mathrm{~kg}$ en los últimos 3 meses. Mostraba signos de mal nutrición y aspecto consuntivo, con marcado edema en ambos miembros inferiores y escoriaciones en la piel. El laboratorio reveló una hipoalbuminemia y anemia normocítica normocrómica. Refirió, además, como antecedente relevante una diarrea
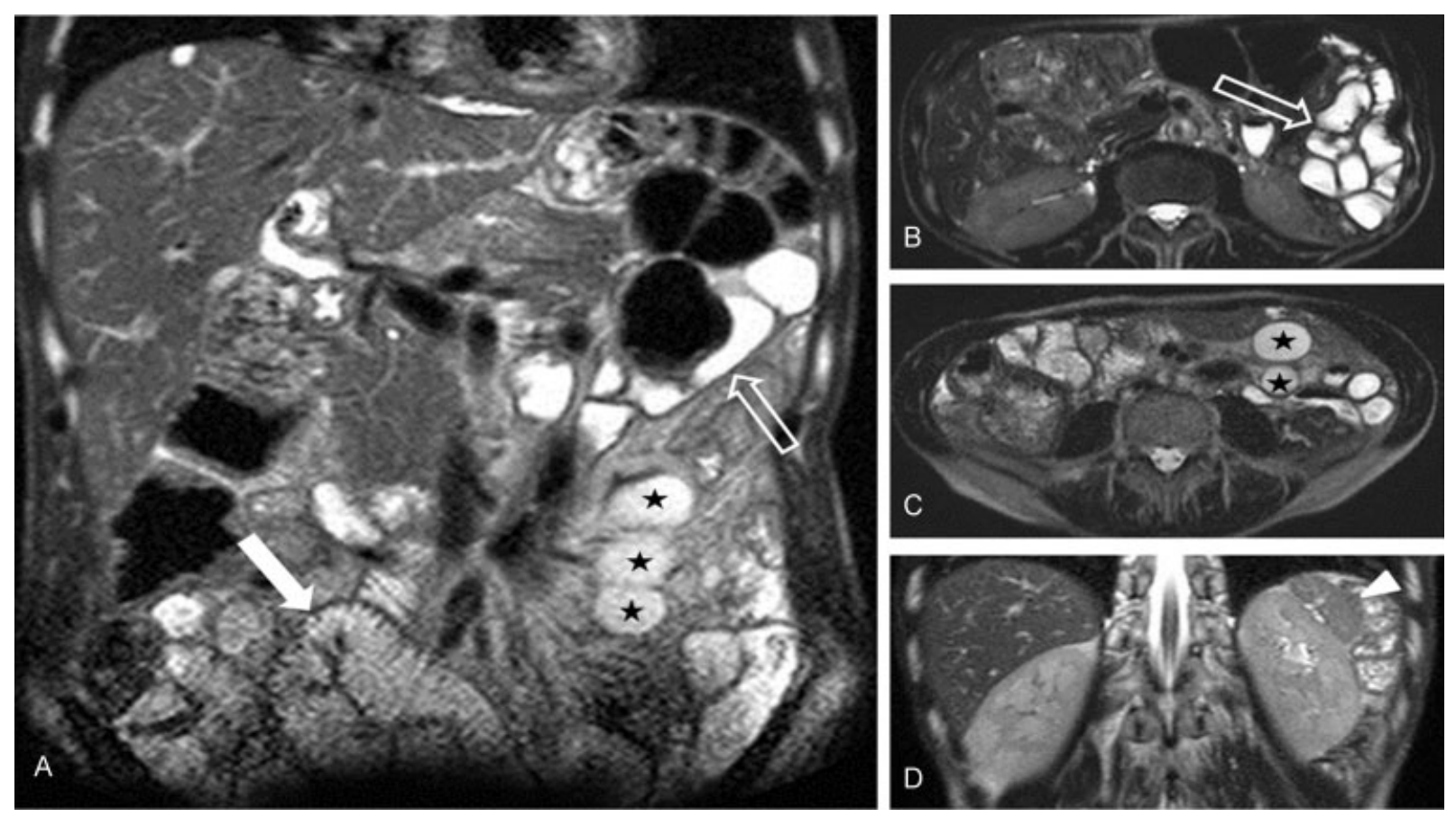

Fig. 1 (A) Coronal ponderado en T2, que muestra asas del intestino delgado distendidas, con atrofia vellositaria en asas de yeyuno (flecha hueca), aumento de las vellosidades en el íleon (flecha blanca) y masas quísticas a nivel de la raíz del mesenterio, compatibles con ganglios cavitados (estrellas). (B y C) Axiales ponderados en T2, que muestran atrofia vellositaria del yeyuno (flecha hueca) y los ganglios mesentéricos cavitados (estrellas). Nótese además el escaso volumen de tejido celular subcutáneo y grasa intraabdominal, en este paciente con desnutrición severa. (D) Coronal ponderado en T2 donde se observa un bazo pequeño comparado con el tamaño renal (cabeza de flecha).

received

April 19, 2017

accepted

August 6, 2017
DOI https://doi.org/

10.1055/s-0038-1637034.

ISSN 1852-9992.
Copyright ( 2019 , Sociedad Argentina de Radiología. Publicado por Thieme Revinter Publicações Ltda., Rio de Janeiro, Brazil. Todos los derechos reservados.

\section{License terms}

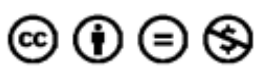


crónica, que se constató durante la internación con características de esteatorrea.

En la resonancia magnética (RM) de abdomen se detectaron como hallazgos positivos un aplanamiento vellositario a nivel del yeyuno, con inversión del patrón de pliegues yeyunoileal. El bazo se encontraba disminuido de tamaño y se observaron además múltiples imágenes de aspecto quístico a nivel de la raíz del mesenterio, compatibles con ganglios cavitados (-Fig. 1). Con esos hallazgos se planteó como posibilidad un síndrome del ganglio mesentérico cavitado como complicación de una enfermedad celíaca no controlada, hallazgo que se confirmaría posteriormente mediante endoscopía con toma de biopsia.

El síndrome del ganglio mesentérico cavitado es una complicación infrecuente de la enfermedad celíaca con pocos casos reportados en la literatura. ${ }^{5}$ Suele asociarse a hipoesplenismo y las series reportadas lo posicionan como un indicador de mal pronóstico, con un índice de mortalidad que se calcula en aproximadamente un $50 \%$, vinculado a la desnutrición severa, linfoma de células $\mathrm{T}$, hemorragia intestinal por úlceras y cuadros sépticos secundarios a hipofunción esplénica. ${ }^{2,4,5} \mathrm{Si}$ bien su causa no es del todo conocida, una de las hipótesis sostiene que el daño en la barrera mucosa del intestino delgado genera una excesiva exposición de los ganglios mesentéricos a los antígenos, causando depleción de células linfoides en los ganglios linfáticos y el bazo. ${ }^{2}$ Otra hipótesis señala que los cambios quísticos pueden reflejar necrosis en los ganglios mesentéricos desencadenada por la activación del complemento y coagulación intravascular. ${ }^{2}$

Los estudios por imágenes revelan estructuras quísticas de contenido con baja atenuación en tomografía computada (TC) que en ocasiones se asocia a un nivel líquido-grasa, hallazgo mejor demostrado en estudios de RM, en donde pueden ser útiles las técnicas de supresión grasa $\mathrm{y}$ desplazamiento químico. ${ }^{2,3}$

Entre los diagnósticos diferenciales se encuentran los linfangiomas quísticos, quistes mesentéricos, y otras causas de ganglios cavitados como la tuberculosis (TBC), enfermedad de Wipple, linfoma y metástasis de tumores de células germinales. ${ }^{2,3}$

La asociación de estructuras quísticas cavitadas con o sin nivel líquido en el mesenterio, sumado a la atrofia vellositaria de yeyuno con inversión del patrón de pliegues yeyuno-ileal y un bazo de pequeño tamaño, debe hacernos pensar en una enfermedad celíaca no controlada.

Confidencialidad de los datos

Los autores declaran que han seguido los protocolos de su centro de trabajo sobre la publicación de datos de pacientes y que todos los pacientes incluidos en el estudio han recibido información suficiente y han dado su consentimiento informado por escrito para participar en dicho estudio.

\section{Conflicto de Intereses}

Los autores del trabajo declaran no tener ningún conflicto de intereses, excepto el Dr. Andrés Domínguez que declara como posible conflicto de interés ser Revisor de la RAR.

\section{Bibliografia}

1 García Novo MD, Garfia C, Acuña Quirós MD, et al. Prevalencia de la enfermedad celiaca en donantes de sangre de la Comunidad de Madrid. Rev Esp Enferm Dig 2007;99(06):337-342

2 Huppert BJ, Farrell MA, Kawashima A, Murray JA. Diagnosis of cavitating mesenteric lymph node syndrome in celiac disease using MRI. AJR Am J Roentgenol 2004;183(05):1375-1377

3 Reddy D, Salomon C, Demos TC, Cosar E. Mesenteric lymph node cavitation in celiac disease. AJR Am J Roentgenol 2002;178(01): 247

4 Howat AJ, McPhie JL, Smith DA, et al. Cavitation of mesenteric lymph nodes: a rare complication of coeliac disease, associated with a poor outcome. Histopathology 1995;27(04):349-354

5 Matuchansky C, Colin R, Hemet J, et al. Cavitation of mesenteric lymph nodes, splenic atrophy, and a flat small intestinal mucosa. Report of six cases. Gastroenterology 1984;87(03):606-614 